\title{
Prevalence of coronary artery disease and its risk factors in Kerala, South India: a community-based cross-sectional study
}

\author{
M. N. Krishnan', G. Zachariah², K. Venugopal ${ }^{3}$, P. P. Mohanan, S. Harikrishnan, G. Sanjay ${ }^{5}$, L. Jeyaseelan ${ }^{6}$ \\ and K. R. Thankappan ${ }^{7^{*}}$
}

\begin{abstract}
Background: There are no recent data on prevalence of coronary artery disease (CAD) in Indians. The last community based study from Kerala, the most advanced Indian state in epidemiological transition, was in 1993 that reported $1.4 \%$ definite CAD prevalence. We studied the prevalence of CAD and its risk factors among adults in Kerala.

Methods: In a community-based cross sectional study, we selected 5167 adults (mean age 51 years, men $40.1 \%$ ) using a multistage cluster sampling method. Information on socio-demographics, smoking, alcohol use, physical activity, dietary habits and personal history of hypertension, diabetes, and CAD was collected using a structured interview schedule. Anthropometry, blood pressure, electrocardiogram, and biochemical investigations were done using standard protocols. CAD and its risk factors were defined using standard criteria. Comparisons of age adjusted prevalence were done using two tailed proportion tests.

Results: The overall age-adjusted prevalence of definite CAD was $3.5 \%$ : men $4.8 \%$, women $2.6 \%(p<0.001)$. Prevalence of any CAD was $12.5 \%$ : men $9.8 \%$, women $14.3 \%(p<0.001)$. There was no difference in definite CAD between urban and rural population. Physical inactivity was reported by 17.5 and $18 \%$ reported family history of CAD. Other CAD risk factors detected in the study were: overweight or obese $59 \%$, abdominal obesity $57 \%$, hypertension $28 \%$, diabetes $15 \%$, high total cholesterol $52 \%$ and low level of high density lipoprotein cholesterol $39 \%$. Current smoking was reported only be men (28\%).

Conclusion: The prevalence of definite CAD in Kerala increased nearly three times since 1993 without any difference in urban and rural areas. Most risk factors of CAD were highly prevalent in the state. Both population and individual level approaches are warranted to address the high level of CAD risk factors to reduce the increasing prevalence of CAD in this population.
\end{abstract}

Keywords: Coronary artery disease, Coronary risk factors, Prevalence, Kerala, India

\section{Background}

Coronary artery disease (CAD) is the foremost cause of disability and death the world over and is one of the top five causes of death in Indian population [1]. Mortality from CAD in Indians is predicted to increase rapidly and overtake that of the high-income countries. Among adults over 20 years of age, there has been a two-fold

\footnotetext{
* Correspondence: kavumpurathu@yahoo.com; kr.thankappan@gmail.com ${ }^{7}$ Achutha Menon Centre for Health Science Studies, Sree Chitra Tirunal Institute for Medical Sciences and Technology, Trivandrum Medical College, P.O. 695011 Thiruvananthapuram, Kerala, India

Full list of author information is available at the end of the article
}

rise in CAD in rural areas and a 6-fold rise in urban areas during the period from 1960 to 2002 [2]. Previous studies have shown high prevalence of CAD in Asian Indians residing in the United States [3]. However there are no robust and contemporary data on CAD in native Indians. In a systematic review of CAD prevalence from India, Ahmed et al. commented that none of the studies conformed to the requirements of a high-quality epidemiologic study [4]. Kerala, with a population of over 33 million, is the most advanced state in epidemiological transition and has the highest prevalence of CAD risk factors in India [5]. The state has been reported to be 
the harbinger of what the rest of India is going to face in the near future [5]. The INTERHEART study reported the importance of conventional risk factors associated with CAD [6]. Although the CAD risk factor prevalence is the highest in the state of Kerala, there are no recent studies on the prevalence of CAD in this state. The only one community based study in 1993 from the rural area of the southernmost district of the state reported a CAD prevalence of $7.4 \%$ [7]. The environment in Kerala is conducive for increasing the CAD risk factors [8] which is likely to result in an increase in the CAD prevalence. Therefore we wanted to study the current prevalence of $\mathrm{CAD}$ and its major risk factors in Kerala.

\section{Methods}

A detailed description of the design, sample, and methods of the study has already been published [9]. Briefly, this was a cross-sectional community-based study during the period from January to June 2011. We estimated the sample size based on an anticipated prevalence of $7.4 \%$ of CAD for rural Kerala based on the data by Kutty et al. [7] and $11 \%$ for urban Kerala based on the study by Mohan et al. in Chennai [10]. The total sample size was estimated to be 3000 in rural and 2400 in urban areas. Sample selection procedure is given in Fig. 1. Subjects aged 20-79 years were selected using a multistage cluster sampling procedure. In the first stage three out of the 14 districts of Kerala state were selected. The 14 districts were grouped into five northern, five southern and four central districts. From the northern group of districts, Kozhikode district was selected which included the city corporation of Kozhikode. In the southern group of districts, Thiruvananthapuram and Kollam districts had city corporations. Of these Thiruvananthapuram was selected randomly. In the central group of districts there were two districts which included corporations; Ernakulam and Thrissur. Of these Thrissur district was selected randomly. In the second stage, one ward was randomly selected from each of the three city corporation wards in the urban area. Each of the selected wards was divided into six geographic regions. One of these geographic regions was selected randomly as the study area. All the households in this area were eligible to be included in this sample. One subject between 20 and 59 years was selected using KISH method [11] and all the subjects between 60 and 79 years were included.

In rural area, two of the Panchayats from the above three districts were randomly selected. From each of these Panchayats, one ward was randomly selected. All the households in the selected ward were eligible to be included on the sample. One subject between the age of 20 and 59 years was selected using KISH method and all subjects between 60 and 79 years were included.

Each selected individual was invited to visit an easily accessible facility with all past medical records after overnight fasting. Trained investigators collected all the relevant data.

Using a structured interview schedule, information on basic socio-economic and demographic details, smoking, physical activity, dietary habits, personal history of hypertension, dyslipidemia, diabetes mellitus and CAD were collected. The instrument also contained the Rose Angina Questionnaire (RAQ) [12, 13] and questions related to history of documented prior myocardial infarction, unstable angina, coronary artery bypass grafting $(\mathrm{CABG})$ surgery, noninvasive investigations for $\mathrm{CAD}$, coronary angiography, coronary angioplasty, documented use of drugs for CAD and hospital admission for CAD. Family history of ischemic heart disease, stroke and coronary risk factors was also recorded.

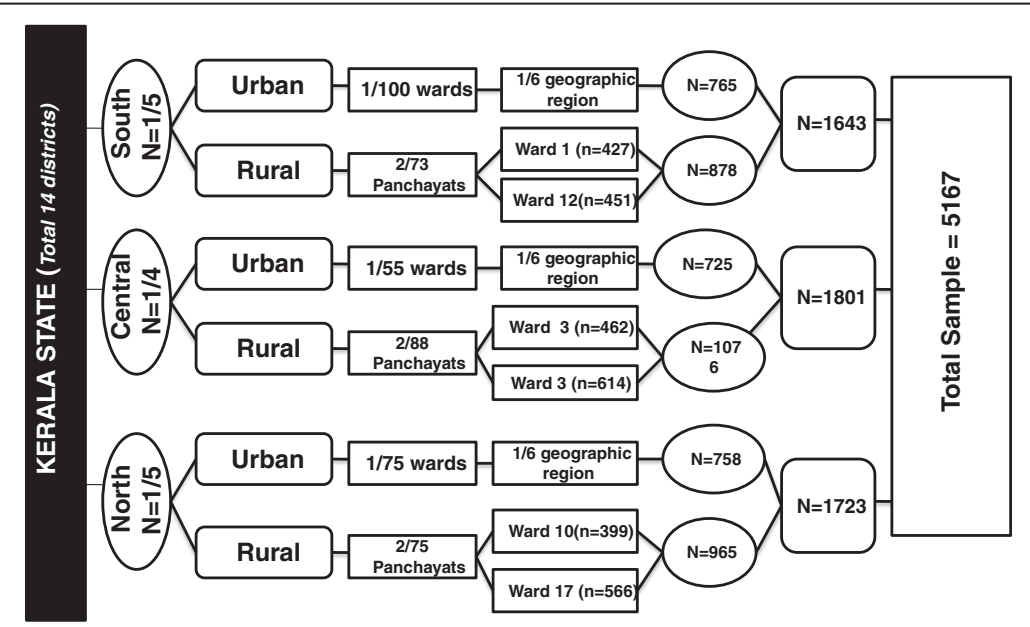

Fig. 1 Sample selection procedure 


\section{Anthropometric measurements}

Height was measured by wall-mounted stadiometer (Model 206, Seca, Hamburg Germany) to the nearest centimeter. Subjects were asked to stand upright without shoes, with their back against the wall, heels together and eyes directed forward.

Weight was measured with a portable electronic weighing scale (Model HN 283, Omron Corporation, Shimogyo-ku, Kyoto, Japan) kept on a firm horizontal surface. The subjects were asked to wear light clothing and remove footwear. Weight was recorded in kilograms to the nearest $0.5 \mathrm{Kg}$. Body mass index was calculated as weight in $\mathrm{kg} /$ (height in meter squared) [14].

Waist circumference was measured using a nonstretchable measuring tape. The subjects were asked to stand erect in a relaxed position with both feet together. Waist girth was measured at the midpoint between the iliac crest and the lower margin of the ribs at the end of expiration, to the nearest centimeter.

\section{Blood pressure}

Blood pressure was recorded with electronic apparatus (model 1A2, Omron Corporation, Shimogyo-ku, Kyoto, Japan) in sitting position, on the left arm resting on a table at heart level, after the subject having rested for at least $15 \mathrm{~min}$. Three readings were taken $3 \mathrm{~min}$ apart and the mean of the last two readings was recorded as the BP. Heart rate was also recorded.

\section{Electrocardiogram}

Resting 12 lead electrocardiogram (ECG) was performed on all subjects by trained technicians with three-channel digital ECG recorders with facility for display and measured parameters. For each lead, five consecutive complexes were recorded. Minnesota coding [15] and application of CAD criteria were performed by an experienced cardiologist for the respective region; those subjects diagnosed to have CAD were re-evaluated by another cardiologist in a blinded manner. Disagreements were resolved by consensus. Similar procedure was followed for $10 \%$ of randomly selected subjects without a diagnosis of CAD.

\section{Biochemical investigations}

Blood samples were drawn from individuals after 10-12 h of fasting. Plasma glucose was estimated immediately, onsite using the Glucose oxidase/ peroxidase- phenol-4amenophenazone method (GOD-PAP). Blood samples for lipid profile measurement were transported on ice packs $\left(4-6{ }^{\circ} \mathrm{C}\right.$ ) to an accredited core laboratory (Thyrocare Technologies Ltd, Navi Mumbai, India) on the same day. Estimation was carried out within $48 \mathrm{~h}$ in clinical chemistry instruments (Olympus AU2700) and Advia 1800 chemistry system (Siemens) using standard commercially available kits (Agappe Diagnostics). Photometry technology was used for lipid profile. Serum cholesterol was measured by cholesterol oxidase phenol 4- aminoantipyrine peroxidase (CHOD-PAP) method and serum triglycerides by glycerol-3 - phosphate oxidase - $\mathrm{p}$ - aminophenzone peroxidase (GPO-PAP) method. High density lipoprotein (HDL) cholesterol was estimated by enzyme selective protection method. The reaction between cholesterol assays is suppressed by the electrostatic interaction between polyanions \& cationic substances. Low-density lipoprotein (LDL) cholesterol was calculated by using Friedwald's equation.

\section{Ethical clearance}

The present study was in compliance with the Helsinki Declaration. The study was approved by the Ethics Committee of Cardiological Society of India, Kerala Chapter. Informed written consent was obtained from all participants.

\section{Definitions used}

We defined coronary artery disease as: (a) Definite CAD based on any of: documented evidence of prior acute coronary syndrome (ACS) or treatment for CAD, documented history of undergoing coronary angioplasty or CABG, more than $50 \%$ epicardial coronary stenosis by invasive coronary angiography, ECG showing pathological Q waves (any of Minnesota code 1-1-1 to 1-1-7 or $1-2-1$ to $1-2-5$ or $1-2-7$ ), imaging evidence of a region of loss of viable myocardium that is thinned and has a motion abnormality, in the absence of a non-ischemic cause [16], RAQ angina plus ECG changes (any of Minnesota codes 4-1-1, 4-1-2, 4-2 or 5-1, 5-2), or RAQ angina plus positive treadmill ECG (exercise-induced horizontal or down-sloping ST depression of $\geq 1 \mathrm{~mm}$ at $80 \mathrm{~ms}$ from J point), or inducible ischemia on stress imaging;(b) Probable CAD based on any of (in the absence of any of the definite criteria): RAQ angina without significant ECG changes, ECG changes (any of Minnesota Code 4-1-1,4-1-2, 4-2 or 5-1, 5-2) without RAQ angina, or positive treadmill ECG without RAQ angina. Any CAD was defined as those who satisfied either definite or probable CAD criteria.

We defined diabetes mellitus as fasting blood glucose value of $\geq 7 \mathrm{mmol} / \mathrm{L}$ and/or if there was current use of medications for diabetes [17], hypertension as blood pressure $\geq 140 \mathrm{~mm}$ of $\mathrm{Hg}$ systolic and/or $\geq 90 \mathrm{~mm}$ of $\mathrm{Hg}$ diastolic and/or currently on drugs for high blood pressure [18], and dyslipidemia as any of: serum total cholesterol $\geq 5.18 \mathrm{mmol} / \mathrm{L}$, serum LDL cholesterol $\geq 3.37 \mathrm{mmol} / \mathrm{L}$, serum HDL cholesterol $<1.04 \mathrm{mmol} / \mathrm{L}$ in men or $<1.29 \mathrm{mmol} / \mathrm{L}$ in women, or serum triglycerides $\geq 1.69 \mathrm{mmol} / \mathrm{L}$ [19]. We categorized body mass index (BMI) as normal (18.0-22.9 kg/m²), 
overweight $\left(23.0-24.9 \mathrm{~kg} / \mathrm{m}^{2}\right)$, or obesity $\left(\geq 25 \mathrm{~kg} / \mathrm{m}^{2}\right)$. Abdominal obesity was defined as a waist circumference of $\geq 90 \mathrm{~cm}$ in men or $\geq 80 \mathrm{~cm}$ in women [20]. Physical activity levels were classified into sedentary and non-sedentary. All subjects reporting physical activity for at least $30 \mathrm{~min}$ a day for a minimum of 5 days a week (household activities involving physical effort, walking to and from work involving at least 30 min., manual workers, those performing leisuretime physical activity) were considered non-sedentary. All others were classified as sedentary [21]. We determined the socioeconomic status of the participants using the validated standard of living Index tool developed by National Family Health Survey [22]. We divided our entire sample into tertiles, based upon the index score. Participants in the upper tertile were classified as high socioeconomic group, those in the middle tertile as intermediate socioeconomic group and lower tertile as low socioeconomic group.

\section{Statistical analysis}

We entered data into CS Pro software (the US Census Bureau) version 4.0 for Windows. Data cleaning and statistical analysis were performed using Stata (Stata Corp, Texas, USA) version $13 \cdot 0$ for Windows. All proportions were age-adjusted using WHO population data. Frequency distribution was done for categorical variables. Comparisons of age-adjusted prevalence between different categories were done using two-tailed proportion test. The difference in the age-adjusted prevalence and its $95 \%$ confidence intervals are provided. $P$ value $<0.05$ defined the level of statistical significance.

\section{Results}

Of the total 6477 individuals contacted, we could evaluate 5167 (men $40.1 \%$ ); overall response rate was $79.8 \%$ (men $75.0 \%$, women $83.3 \%$ ). There were no missing data in the interview schedule, ECG or anthropometrics. Data on blood sugar and serum cholesterol were missing in 32 and 47 subjects respectively; these were excluded from analysis.

Table 1 depicts the demographic and behavioural characteristics of the participants by area. There were greater proportion of participants without formal education in rural area as compared to urban; those with $>10$ years of education were more in urban as compared to rural area. The proportion of subjects that reported current smoking was similar in rural and urban men. There was larger proportion of vegetarianism, obesity and abdominal obesity among urban participants.

\section{Prevalence of coronary artery disease}

The crude and age-adjusted prevalence of definite CAD in Kerala was 5.8 and $3.5 \%$ respectively. The figures for men were $8.0 \%$ and $4.8 \%$ and for women 4.2 and $2.6 \%$ respectively; the differences were significant across gender $(p<0.001)$. The overall crude and age-adjusted prevalence of any CAD in Kerala was 16.6 and $12.5 \%$ respectively. The crude and age-adjusted prevalence of any $\mathrm{CAD}$ in men were 14.6 and $9.8 \%$ and in women were 17.9 and $14.3 \%$ respectively; the prevalence was significantly higher in women as compared to men $(p<0.001)$. Table 2 outlines the prevalence of CAD (any \& definite) among different age groups and gender. As age increased, the prevalence of CAD increased in both gender.

The prevalence of definite CAD was similar irrespective of region or religion. The prevalence of any CAD was lowest among Christians and highest among Muslims (10 vs.15.8 \% $p=0 \cdot 002$ ). Of the three geographical regions of Kerala, Thirvananthapuram had lower prevalence of any CAD compared to Thrissur and Kozhikode (8.3 vs. 14.4 and $14.7 \% p<0.001$ ).

Table 3 depicts the age-adjusted prevalence of CAD (any and definite) by gender, age group (age $\leq 45$ and $>45$ years), and by area. Age-adjusted prevalence of any CAD in participants $\leq 45$ years and $>45$ years was 7.8 and $18.7 \%$ respectively. Similarly the age-adjusted prevalence of definite CAD was $0.9 \%$ in participants $\leq 45$ years and $6.8 \%$ in $>45$ years. Age-adjusted prevalence of CAD (any and definite) was significantly higher in participants $>45$ years $(p<0.001)$. The prevalence of any CAD was significantly higher in rural women $(15.6 \%)$ as compared to urban women $(11.7 \%)(p<0.01)$. The overall prevalence of any CAD was higher in rural $(13.2 \%)$ than urban $(11 \cdot 3 \%)$ area $(p=0.038)$. However, there was no difference between urban and rural areas in the overall prevalence of definite CAD (3.4 vs. $3.6 \%)(p=0.72)$.

Table 4 shows the age-adjusted prevalence of various criteria for diagnosis of CAD. ST code, T code, and RAQ angina were significantly higher in women; all other criteria were higher in men $(p<0.01)$. Table 5 represents the age-adjusted prevalence of various criteria for diagnosis of CAD among participants with any CAD. Again, most of the definite criteria for CAD were higher in men. Except ST code, T code, and RAQ angina, there was higher prevalence of various coronary artery criteria among men as compared to women $(p<0.001)$; ST code was higher in women, while $\mathrm{T}$ code and RAQ angina showed no significant difference. Among participants diagnosed to have any CAD, the prevalence of known CAD was 7.8 and $2.7 \%$ in men and women respectively. Symptomatic CAD (sum of those with known CAD and RAQ angina) was prevalent in $54 \%$ with any CAD.

\section{Coronary risk factors}

Age-adjusted prevalence of major risk factors of CAD by gender and area is presented in Table 6. Conventional 
Table 1 Baseline demographic and behavioural characteristics of the participants by area

\begin{tabular}{|c|c|c|c|c|c|c|c|c|}
\hline \multirow[t]{2}{*}{ Variable } & & \multicolumn{2}{|c|}{$\begin{array}{l}\text { Urban } \\
(N=2248)\end{array}$} & \multicolumn{2}{|c|}{$\begin{array}{l}\text { Rural } \\
(N=2919) \\
\end{array}$} & \multicolumn{2}{|c|}{$\begin{array}{l}\text { Total } \\
(N=5167)\end{array}$} & \multirow[b]{2}{*}{$P$ value } \\
\hline & & $\bar{n}$ & (\%) & n & (\%) & n & (\%) & \\
\hline \multicolumn{9}{|l|}{$\overline{\text { Age }}$} \\
\hline & $20-29$ & 111 & 4.94 & 225 & 7.71 & 336 & 6.50 & \multirow[t]{6}{*}{$<0.001$} \\
\hline & $30-39$ & 345 & 15.35 & 543 & 18.60 & 888 & 17.19 & \\
\hline & $40-49$ & 507 & 22.55 & 692 & 23.71 & 1199 & 23.20 & \\
\hline & $50-59$ & 493 & 21.93 & 531 & 18.19 & 1024 & 19.82 & \\
\hline & $60-69$ & 566 & 25.18 & 650 & 22.27 & 1216 & 23.53 & \\
\hline & $70-79$ & 226 & 10.05 & 278 & 9.52 & 504 & 9.75 & \\
\hline \multicolumn{9}{|l|}{ Sex } \\
\hline & Men & 971 & 43.19 & 1101 & 37.72 & 2072 & 40.10 & \multirow[t]{2}{*}{$<0.001$} \\
\hline & Women & 1277 & 56.81 & 1818 & 62.28 & 3095 & 59.90 & \\
\hline \multicolumn{9}{|c|}{ Socio-economic status } \\
\hline & Low & 630 & 28.02 & 1303 & 44.64 & 1933 & 37.41 & \multirow[t]{3}{*}{$<0.001$} \\
\hline & Middle & 792 & 35.23 & 743 & 25.45 & 1535 & 29.71 & \\
\hline & High & 826 & 36.74 & 873 & 29.91 & 1699 & 32.88 & \\
\hline \multicolumn{9}{|c|}{ Educational status } \\
\hline & No formal education & 87 & 3.87 & 203 & 6.95 & 290 & 5.61 & \multirow[t]{4}{*}{$<0.001$} \\
\hline & $1-4$ years & 208 & 9.25 & 437 & 14.97 & 645 & 12.48 & \\
\hline & $5-10$ years & 1294 & 57.56 & 1729 & 59.23 & 3023 & 58.51 & \\
\hline & $>10$ years & 659 & 29.31 & 550 & 18.84 & 1209 & 23.40 & \\
\hline \multicolumn{9}{|c|}{ Smoking ${ }^{a}$} \\
\hline & Never & 523 & 55.52 & 443 & 44.04 & 966 & 49.59 & \multirow[t]{3}{*}{$<0.001$} \\
\hline & Past & 111 & 11.78 & 220 & 21.87 & 331 & 16.99 & \\
\hline & Current & 308 & 32.70 & 343 & 34.10 & 651 & 33.42 & \\
\hline \multicolumn{9}{|c|}{ Physical activity } \\
\hline & Sedentary & 1770 & 78.74 & 2328 & 79.75 & 4098 & 79.31 & \multirow[t]{2}{*}{0.371} \\
\hline & Non-sedentary & 478 & 21.26 & 591 & 20.25 & 1069 & 20.69 & \\
\hline \multicolumn{9}{|c|}{ Dietary habits } \\
\hline & Vegetarian & 161 & 7.16 & 110 & 3.77 & 271 & 5.24 & \multirow[t]{2}{*}{$<0.001$} \\
\hline & Non-vegetarian & 2087 & 92.84 & 2809 & 96.23 & 4896 & 94.76 & \\
\hline \multicolumn{9}{|l|}{ BMl } \\
\hline & Low & 111 & 4.95 & 244 & 8.37 & 355 & 6.88 & \multirow[t]{4}{*}{$<0.001$} \\
\hline & Normal & 685 & 30.53 & 1042 & 35.76 & 1727 & 33.48 & \\
\hline & Overweight & 450 & 20.05 & 527 & 18.09 & 977 & 18.94 & \\
\hline & Obese & 998 & 44.47 & 1101 & 37.78 & 2099 & 40.69 & \\
\hline \multicolumn{9}{|c|}{ Abdominal Obesity } \\
\hline & Yes & 1394 & 62.20 & 1709 & 58.67 & 3103 & 60.21 & \multirow[t]{2}{*}{$<0.001$} \\
\hline & No & 847 & 37.80 & 1204 & 41.33 & 2051 & 39.79 & \\
\hline
\end{tabular}

${ }^{a}$ Smoking in men only

risk factors like diabetes mellitus, hypertension, high serum cholesterol, low serum HDL cholesterol, smoking, physical inactivity, and family history of CAD were highly prevalent in the state. Except low HDL cholesterol $(23.9 \%$ in urban men vs. $27.6 \%$ in rural men), all other major risk factors were higher in urban men as compared to rural men. This pattern was also observed in urban women as compared to 
Table 2 Crude and age-adjusted prevalence of CAD by age group and gender

\begin{tabular}{|c|c|c|c|c|c|c|c|c|c|}
\hline \multirow{2}{*}{$\begin{array}{l}\text { Age group (yrs.) } \\
\text { Any CAD }\end{array}$} & \multicolumn{3}{|l|}{ Men } & \multicolumn{3}{|c|}{ Women } & \multirow[t]{2}{*}{ Difference (\%) } & \multirow[t]{2}{*}{$95 \% \mathrm{Cl}$} & \multirow[t]{2}{*}{$p$ value } \\
\hline & $\mathrm{n}$ & $\mathrm{P}(\%)$ & SE & $\bar{n}$ & $P(\%)$ & SE & & & \\
\hline $20-29$ & 144 & 2.78 & 1.37 & 192 & 7.29 & 1.88 & -4.51 & $(-9.07,0.04)$ & 0.069 \\
\hline $30-39$ & 306 & 6.54 & 1.42 & 582 & 8.93 & 1.18 & -2.40 & $(-6.01,1.21)$ & 0.213 \\
\hline $40-49$ & 465 & 7.10 & 1.19 & 734 & 14.44 & 1.30 & -7.34 & $(-10.80,-3.89)$ & $<0.001$ \\
\hline $50-59$ & 386 & 12.44 & 1.68 & 638 & 19.91 & 1.58 & -7.47 & $(-11.99,-2.95)$ & 0.002 \\
\hline $60-69$ & 537 & 22.72 & 1.81 & 679 & 25.77 & 1.68 & -3.05 & $(-7.89,1.78)$ & 0.218 \\
\hline 70-79 & 234 & 32.05 & 3.06 & 270 & 29.26 & 2.77 & 2.79 & $(-5.28,10.87)$ & 0.497 \\
\hline All & 2072 & 14.58 & 0.78 & 3095 & 17.87 & 0.69 & -3.29 & $(-5.32,-1.26)$ & 0.002 \\
\hline Age adjusted & 2072 & 9.80 & 0.65 & 3095 & 14.26 & 0.69 & -4.46 & $(-6.24,-2.69)$ & $<0.001$ \\
\hline \multicolumn{10}{|l|}{ Definite CAD } \\
\hline $20-29$ & 144 & 0.00 & 0.00 & 192 & 0.00 & 0.00 & - & - & - \\
\hline $30-39$ & 306 & 2.29 & 0.86 & 582 & 0.52 & 0.30 & 1.77 & $(0.00,3.55)$ & 0.017 \\
\hline $40-49$ & 465 & 3.87 & 0.90 & 734 & 1.77 & 0.49 & 2.10 & $(0.10,4.10)$ & 0.026 \\
\hline $50-59$ & 386 & 6.48 & 1.25 & 638 & 3.13 & 0.69 & 3.34 & $(0.54,6.14)$ & 0.012 \\
\hline $60-69$ & 537 & 13.41 & 1.47 & 679 & 8.98 & 1.10 & 4.42 & $(0.83,8.02)$ & 0.014 \\
\hline $70-79$ & 234 & 18.80 & 2.56 & 270 & 12.59 & 2.02 & 6.21 & $(-0.17,12.59)$ & 0.055 \\
\hline All & 2072 & 8.01 & 0.60 & 3095 & 4.23 & 0.36 & 3.78 & $(2.41,5.15)$ & $<0.001$ \\
\hline Age adjusted & 2072 & 4.80 & 0.39 & 3095 & 2.63 & 0.23 & 2.17 & $(1.09,3.25)$ & $<0.001$ \\
\hline
\end{tabular}

$C A D$ coronary artery disease, $P$ prevalence, $S E$ standard error

rural women except high serum cholesterol $(49.2$ vs. $\quad(p$ value $<0.01)$. However, higher cholesterol and smok$52.4 \% ; p=0.089)$ and low HDL cholesterol (43.4 vs. ing were higher in no CAD group. In definite CAD, all $48.7 \% ; p=0.004)$.

Risk factor analysis of any and definite CAD is presented in Table 7. The age adjusted prevalence of risk factors such as hypertension, low HDL and family history were significantly higher in any CAD group risk factors except low HDL were statistically significant ( $p$ value $<0.01$ ). In addition, excluding higher cholesterol all age adjusted prevalence of these conventional risk factors was higher in definite CAD as compared to no CAD.

Table 3 Age-adjusted prevalence of CAD by gender, age, and area

\begin{tabular}{|c|c|c|c|c|c|c|c|c|c|c|}
\hline & \multirow[t]{2}{*}{ Gender } & \multicolumn{3}{|c|}{$=/<45$ years } & \multicolumn{3}{|c|}{$>45$ years } & \multirow[t]{2}{*}{ Difference (\%) } & \multirow[t]{2}{*}{$95 \% \mathrm{Cl}$} & \multirow[t]{2}{*}{$p$ value } \\
\hline & & $n$ & P (\%) & SE & $\mathrm{n}$ & P (\%) & SE & & & \\
\hline \multirow[t]{3}{*}{ Any CAD } & Men & 728 & 5.12 & 0.82 & 1344 & 15.05 & 1.04 & -9.92 & $(-12.42,-7.43)$ & $<0.001$ \\
\hline & Women & 1239 & 9.48 & 0.92 & 1856 & 21.08 & 1.10 & -11.60 & $(-14.07,-9.13)$ & $<0.001$ \\
\hline & All & 1967 & 7.78 & 0.64 & 3200 & 18.68 & 0.78 & -10.90 & $(-12.69,-9.10)$ & $<0.001$ \\
\hline \multirow[t]{4}{*}{ Definite CAD } & Men & 728 & 1.82 & 0.43 & 1344 & 8.43 & 0.80 & -6.61 & $(-8.39,-4.84)$ & $<0.001$ \\
\hline & Women & 1239 & 0.36 & 0.15 & 1856 & 5.61 & 0.58 & -5.25 & $(-6.35,-4.15)$ & $<0.001$ \\
\hline & All & 1967 & 0.89 & 0.18 & 3200 & 6.80 & 0.47 & -5.91 & $(-6.88,-4.95)$ & $<0.001$ \\
\hline & & Urban & & & Rural & & & & & \\
\hline \multirow[t]{3}{*}{ Any CAD } & Men & 971 & 10.82 & 1.06 & 1101 & 8.94 & 0.81 & 1.88 & $(-0.70,4.46)$ & 0.151 \\
\hline & Women & 1277 & 11.66 & 0.88 & 1818 & 15.63 & 0.94 & -3.97 & $(-6.40,-1.55)$ & 0.002 \\
\hline & All & 2248 & 11.31 & 0.68 & 2919 & 13.23 & 0.66 & -1.92 & $(-3.72,-0.12)$ & 0.038 \\
\hline \multirow[t]{3}{*}{ Definite CAD } & Men & 971 & 4.92 & 0.57 & 1101 & 4.69 & 0.54 & 0.23 & $(-1.62,2.08)$ & 0.806 \\
\hline & Women & 1277 & 2.24 & 0.29 & 1818 & 2.84 & 0.33 & -0.60 & $(-1.72,0.51)$ & 0.299 \\
\hline & All & 2248 & 3.38 & 0.29 & 2919 & 3.57 & 0.28 & -0.18 & $(-1.19,0.82)$ & 0.722 \\
\hline
\end{tabular}


Table 4 Age-adjusted prevalence of various CAD parameters among the total participant population

\begin{tabular}{|c|c|c|c|c|c|c|c|c|c|}
\hline & \multirow{2}{*}{\multicolumn{2}{|c|}{$\frac{\text { Total }}{n=5167}$}} & \multirow{2}{*}{\multicolumn{2}{|c|}{$\frac{\text { Men }}{n=2072}$}} & \multirow{2}{*}{\multicolumn{2}{|c|}{$\frac{\text { Women }}{n=3095}$}} & \multirow[t]{3}{*}{ Difference (\%) } & \multirow[t]{3}{*}{$95 \% \mathrm{Cl}$} & \multirow[t]{3}{*}{$p$ value } \\
\hline & & & & & & & & & \\
\hline & $\mathrm{P}(\%)$ & SE & $\mathrm{P}(\%)$ & SE & $\mathrm{P}(\%)$ & SE & & & \\
\hline Q codes & 0.87 & 0.11 & 1.65 & 0.24 & 0.32 & 0.08 & 1.33 & $(0.74,1.91)$ & $<0.001$ \\
\hline ST Code & 1.87 & 0.19 & 1.00 & 0.18 & 2.46 & 0.29 & -1.47 & $(-2.16,-0.77)$ & $<0.001$ \\
\hline T code & 5.46 & 0.35 & 3.86 & 0.46 & 6.44 & 0.49 & -2.59 & $(-3.79,-1.39)$ & $<0.001$ \\
\hline Documented ACS & 1.59 & 0.14 & 2.70 & 0.30 & 0.84 & 0.13 & 1.86 & $(1.09,2.63)$ & $<0.001$ \\
\hline Documented treatment for CAD & 2.26 & 0.16 & 3.55 & 0.34 & 1.39 & 0.16 & 2.17 & $(1.27,3.07)$ & $<0.001$ \\
\hline Angioplasty/CABG or Fibrinolysis & 0.44 & 0.07 & 0.96 & 0.17 & 0.05 & 0.03 & 0.91 & $(0.48,1.34)$ & $<0.001$ \\
\hline Angiographic Coronary stenosis & 0.63 & 0.09 & 1.15 & 0.19 & 0.27 & 0.07 & 0.88 & $(0.39,1.37)$ & $<0.001$ \\
\hline Imaging evidence of RWMA & 0.06 & 0.09 & 1.34 & 0.20 & 0.10 & 0.05 & 1.24 & $(0.73,1.74)$ & $<0.001$ \\
\hline RAQ angina & 6.38 & 0.35 & 4.71 & 0.44 & 7.47 & 0.51 & -2.76 & $(-4.06,-1.46)$ & $<0.001$ \\
\hline Positive treadmill ECG & 0.54 & 0.08 & 0.98 & 0.17 & 0.22 & 0.07 & 0.76 & $(0.30,1.21)$ & $<0.001$ \\
\hline
\end{tabular}

\section{Discussion}

\section{Prevalence of coronary artery disease}

Coronary artery disease has been gaining importance as a major public health problem in India. In 2003, the prevalence of CAD was estimated to be $3-4 \%$ in rural areas and 8-10\% in urban areas according to a population-based cross sectional survey [23]. Our study also showed high prevalence of CAD in Kerala. The ageadjusted overall prevalence of definite CAD was $3.5 \%$ and any CAD was $12.5 \%$. We chose criteria for any CAD to detect all possible cases of CAD; for definite CAD we have avoided less specific criteria like RAQ angina, positive treadmill electrocardiogram or minor electrocardiographic changes in isolation and used combined criteria when these less specific components were incorporated.
Age-adjusted prevalence of definite CAD was higher in men. However, any CAD prevalence in women was significantly higher than in men. It is well known that women commonly have ECG with nonspecific ST -T changes and angina with normal coronary arteries; this may have resulted in overestimation of any CAD prevalence in women. In our study the prevalence of RAQ angina and ST-T changes were significantly higher among women whose proportion in rural area (62\%) was higher than that of urban area (57\%). Earlier population studies also consistently recorded much higher prevalence of CAD in women using RAQ angina and ST-T criteria for diagnosis of CAD [24-27]. It has also been noted that RAQ angina is less reliable in women [28] and non-white population [29]. Moreover, Patel et al. in a study from migrant South Asians observed that the

Table 5 Age-adjusted prevalence of various CAD parameters among any CAD

\begin{tabular}{|c|c|c|c|c|c|c|c|c|c|}
\hline & \multicolumn{2}{|c|}{$\begin{array}{l}\text { Total } \\
n=855\end{array}$} & \multicolumn{2}{|c|}{$\begin{array}{l}\text { Men } \\
n=302\end{array}$} & \multicolumn{2}{|c|}{$\begin{array}{l}\text { Women } \\
n=553\end{array}$} & \multirow[t]{2}{*}{ Difference (\%) } & \multirow[t]{2}{*}{$95 \% \mathrm{Cl}$} & \multirow[t]{2}{*}{$p$ value } \\
\hline & $P(\%)$ & SE & $\mathrm{P}(\%)$ & SE & $\mathrm{P}(\%)$ & SE & & & \\
\hline Q codes & 4.88 & 0.79 & 12.22 & 2.48 & 1.49 & 0.40 & 10.74 & $(6.91,14.57)$ & $<0.001$ \\
\hline ST Code & 12.94 & 2.16 & 7.08 & 1.51 & 15.14 & 2.74 & -8.07 & $(-12.23,-3.91)$ & $<0.001$ \\
\hline T code & 43.06 & 3.44 & 45.84 & 6.35 & 42.61 & 3.92 & 3.23 & $(-3.74,10.20)$ & 0.3625 \\
\hline Documented ACS & 8.68 & 0.98 & 20.36 & 2.85 & 3.80 & 0.71 & 16.56 & $(11.75,21.37)$ & $<0.001$ \\
\hline Documented treatment for CAD & 11.88 & 1.05 & 26.56 & 2.95 & 5.98 & 0.79 & 20.59 & $(15.23,25.94)$ & $<0.001$ \\
\hline Angioplasty/CABG or Fibrinolysis & 2.18 & 0.41 & 6.63 & 1.44 & 0.19 & 0.11 & 6.43 & $(3.60,9.26)$ & $<0.001$ \\
\hline Angiographic Coronary stenosis & 3.21 & 0.55 & 8.07 & 1.81 & 1.10 & 0.31 & 6.98 & $(3.78,10.17)$ & $<0.001$ \\
\hline Imaging evidence of RWMA & 3.03 & 0.46 & 8.75 & 1.56 & 0.40 & 0.19 & 8.34 & $(5.11,11.57)$ & $<0.001$ \\
\hline RAQ angina & 49.69 & 3.44 & 43.98 & 6.43 & 51.60 & 3.96 & -7.62 & $(-14.60,-0.64)$ & 0.033 \\
\hline Positive treadmill ECG & 2.74 & 0.52 & 6.26 & 1.33 & 1.12 & 0.51 & 5.14 & $(2.27,8.01)$ & $<0.001$ \\
\hline
\end{tabular}

Q code-any of the Minnesota Q code 1-1-1 to 1-1-7 or 1-2-1 to 1-2-5 or 1-2-7; ST code-any of the Minnesota ST code 4-1-1,4-1-2 or 4-2; T code -any of the Minnesota T code 5-1 or 5-2; ACS acute coronary syndrome, CABG coronary artery bypass graft surgery, RWMA regional wall motion abnormality, $E C G$ electrocardiogram, $P$ prevalence, $S E$ standard error 
Table 6 Age adjusted prevalence of major risk factors of CAD by gender and area

\begin{tabular}{|c|c|c|c|c|c|c|c|c|c|c|c|c|c|c|c|c|c|c|}
\hline \multirow[t]{3}{*}{ Risk factor } & \multicolumn{3}{|l|}{ All } & \multicolumn{7}{|l|}{ Men } & \multicolumn{7}{|c|}{ Women } & \multirow[t]{3}{*}{$p$ value ${ }^{* *}$} \\
\hline & \multirow[b]{2}{*}{$\mathrm{n}$} & \multirow[b]{2}{*}{$\%$} & \multirow[b]{2}{*}{ SE } & \multicolumn{3}{|c|}{ Urban } & \multicolumn{3}{|l|}{ Rural } & \multirow[t]{2}{*}{$p$ value ${ }^{*}$} & \multicolumn{3}{|c|}{ Urban } & \multicolumn{3}{|l|}{ Rural } & \multirow[t]{2}{*}{$p$ value ${ }^{*}$} & \\
\hline & & & & $n$ & $\%$ & SE & $\mathrm{n}$ & $\%$ & SE & & $\mathrm{n}$ & $\%$ & SE & $n$ & $\%$ & SE & & \\
\hline Diabetes & 5135 & 15.23 & 0.50 & 962 & 19.14 & 1.40 & 1097 & 16.23 & 1.16 & 0.0831 & 1272 & 15.40 & 0.95 & 1804 & 12.47 & 0.73 & 0.020 & $<0.001$ \\
\hline Hypertension & 5153 & 28.44 & 0.63 & 967 & 39.99 & 2.04 & 1095 & 26.24 & 1.33 & $<0.001$ & 1275 & 30.15 & 1.29 & 1816 & 23.42 & 0.85 & $<0.001$ & $<0.001$ \\
\hline High cholesterol & 5121 & 52.31 & 0.88 & 960 & 56.54 & 2.22 & 1092 & 53.36 & 1.85 & 0.1487 & 1264 & 49.23 & 1.76 & 1805 & 52.35 & 1.35 & 0.089 & 0.023 \\
\hline Low HDL & 5120 & 38.55 & 0.88 & 959 & 23.92 & 1.94 & 1092 & 27.56 & 1.69 & 0.0603 & 1264 & 43.41 & 2.02 & 1805 & 48.73 & 1.44 & 0.004 & $<0.001$ \\
\hline Smoking & 2072 & 28.05 & 1.19 & 971 & 30.45 & 2.00 & 1101 & 26.88 & 1.48 & 0.0721 & - & - & - & - & - & - & - & - \\
\hline Physical inactivity & 5167 & 17.45 & 0.64 & 971 & 30.72 & 2.06 & 1101 & 28.77 & 1.64 & 0.3315 & 1277 & 11.19 & 1.19 & 1818 & 9.38 & 0.64 & 0.101 & $<0.001$ \\
\hline Family history & 5167 & 18.35 & 0.64 & 971 & 18.97 & 1.47 & 1101 & 17.37 & 1.39 & 0.3467 & 1277 & 20.37 & 1.39 & 1818 & 16.92 & 1.02 & 0.015 & 0.939 \\
\hline
\end{tabular}

$P$ prevalence, $S E$ standard error, ${ }^{*} p$ value between urban and rural; ${ }^{* *} p$ value between men and women

value of ST-T changes alone as indicator of CAD was questionable, especially in women [30].

This study showed no difference in the prevalence of definite CAD between urban and rural population of Kerala while any CAD was slightly more in the rural population. Previous studies from other parts of India have highlighted the marked urban preponderance of CAD [25, 31, 32]. Some of the risk factors such as general obesity and abdominal obesity were higher in urban areas, whereas smoking was higher in rural area. There was no difference in physical inactivity in rural and urban areas. In most other Indian states there are huge differences between urban and rural areas. However, in Kerala these differences are either minimal or some risk factors are higher in urban while others are higher in rural as noted above. This could be the reason for not having significant difference of definite CAD prevalence in urban and rural areas of Kerala.

The overall age-adjusted prevalence of any CAD in subjects at or below the age of 45 years was $7.8 \%$. Our study showed a higher prevalence of CAD among young subjects compared to a previous study [7]; in this 1993 study, there were no subjects with definite CAD below the age of 45 years where as we found definite CAD in $0.9 \%$. It is well known that coronary artery disease occurs in Indians 5-10 years earlier [33, 34]. The average age of first myocardial infarction in Asians is 53 years; among the three Asian populations, Chinese, Malay, and Indian, the highest age-adjusted incidence of coronary events in both sexes was in Indians [6]. The ageadjusted prevalence of CAD in young subjects in our study was similar to the US data on prevalence of CAD in the young (1.2\%).

Comparisons with previous Indian studies on CAD prevalence may be problematic due to heterogeneity in period of study, sample characteristics, and criteria for diagnosis of CAD. We did a systematic search for articles in PubMed and EMBASE published during the period from 1990 to 2014 in English language on the prevalence of CAD in India by community-based surveys. We chose only studies that had a minimum sample size of 1000, and that based the diagnosis on documented history of CAD and ECG criteria. We could collect 11original articles, one systematic review [4] and one meta-analysis [35]. The studies were heterogeneous in terms of sampling methods, subject groups, and criteria for diagnosis. Most of the studies were from northern India. Only one study mentioned the period of field survey [25]. Only one study analyzed the data for definite CAD and probable CAD separately [7]. Most studies were on either rural or urban population; only four covered both the groups $[25,31,32,36]$. Sample size calculations were reported in three studies [7, 25, 31]. In a study from Delhi during the period from 1984 to 1987, Chadda et al. reported unadjusted prevalence of $9.7 \%$ in urban and $2.7 \%$ in rural inhabitants [25]. The sample consisted of men and women aged 2464 years; they used clinical history of CAD and electrocardiographic criteria for diagnosis of CAD. Gupta et al. published an epidemiological survey of urban inhabitants over 20 years of age in Rajasthan, India [27]. The prevalence of CAD was $7.6 \%$ (6 \% in men and $10.4 \%$ in women). The age distribution of the sample was consistent with that of the population. Singh et al. in 1997 surveyed an urban and rural sample of 3575 subjects between the ages 25 and 64 years from North India and reported CAD prevalence of 9 and $3.3 \%$ respectively [31]. Mohan and colleagues reported $9 \%$ age-adjusted prevalence of CAD in an urban sample of Chennai, South India [10]. More recently, another study from India noted $12.6 \%$ crude CAD prevalence in an urban population [37]. All these studies had used less specific criteria for diagnosis of CAD; definite CAD as we had analyzed had not been computed in these studies. A study from Pakistan showed a crude prevalence of definite CAD in 6.1 men and $4 \%$ women; they found ischemic ECG changes much more prevalent in women [38]. 
Table 7 Risk factors analysis of any and definite CAD

\begin{tabular}{|c|c|c|c|c|c|c|c|c|c|c|c|c|c|c|c|c|c|c|}
\hline \multirow[t]{3}{*}{ Risk factor } & \multicolumn{9}{|c|}{ Any CAD } & \multicolumn{9}{|c|}{ Definite CAD } \\
\hline & \multicolumn{3}{|l|}{ Yes } & \multicolumn{3}{|l|}{ No } & \multirow[t]{2}{*}{ Difference (\%) } & \multirow[t]{2}{*}{$95 \% \mathrm{Cl}$} & \multirow[t]{2}{*}{$p$ value } & \multicolumn{3}{|l|}{ Yes } & \multicolumn{3}{|l|}{ No } & \multirow[t]{2}{*}{ Difference (\%) } & \multirow[t]{2}{*}{$95 \% \mathrm{Cl}$} & \multirow[t]{2}{*}{$p$ value } \\
\hline & $n$ & $\%$ & SE & $n$ & $\%$ & SE & & & & $n$ & $\%$ & SE & $n$ & $\%$ & SE & & & \\
\hline Diabetes & 851 & 17.07 & 1.97 & 4284 & 14.89 & 0.52 & 2.18 & $(-0.56,4.93)$ & 0.106 & 296 & 33.30 & 5.24 & 4839 & 14.73 & 0.50 & 18.57 & $(13.11,24.03)$ & $<0.001$ \\
\hline Hypertension & 852 & 32.19 & 2.04 & 4301 & 27.67 & 0.67 & 4.51 & $(1.10,7.92)$ & 0.008 & 295 & 51.32 & 5.34 & 4858 & 28.04 & 0.64 & 23.29 & $(17.44,29.13)$ & $<0.001$ \\
\hline High cholesterol & 849 & 47.63 & 3.24 & 4272 & 52.82 & 0.92 & -5.19 & $(-8.86,-1.51)$ & 0.006 & 293 & 41.01 & 5.68 & 4828 & 53.01 & 0.88 & -12.00 & $(-17.81,-6.20)$ & $<0.001$ \\
\hline Low HDL & 849 & 43.62 & 3.53 & 4271 & 37.59 & 0.92 & 6.04 & $(2.40,9.68)$ & 0.001 & 293 & 42.76 & 5.90 & 4827 & 38.33 & 0.89 & 4.44 & $(-1.39,10.26)$ & 0.13 \\
\hline Smoking & 855 & 6.91 & 1.02 & 4312 & 11.80 & 0.56 & -4.89 & $(-6.85,-2.94)$ & $<0.001$ & 297 & 15.69 & 4.42 & 4870 & 11.22 & 0.53 & 4.46 & $(0.23,8.69)$ & 0.019 \\
\hline Physical inactivity & 855 & 15.55 & 2.17 & 4312 & 17.49 & 0.68 & -1.94 & $(-4.62,0.74)$ & 0.170 & 297 & 31.02 & 5.32 & 4870 & 17.13 & 0.65 & 13.89 & $(8.52,19.25)$ & $<0.001$ \\
\hline Family history & 855 & 27.06 & 3.09 & 4312 & 17.37 & 0.66 & 9.70 & $(6.51,12.88)$ & $<0.001$ & 297 & 25.29 & 4.06 & 4870 & 18.03 & 0.65 & 7.27 & $(2.21,12.33)$ & 0.002 \\
\hline
\end{tabular}


The US statistics reported $6 \%$ age-adjusted CAD prevalence in respondents above 18 years by survey based on self-reported CAD by telephonic interview [39]. The prevalence between ages 18-44 years was $1.2 \%$. The update on heart disease and stroke in the US reported CAD prevalence of $6.4 \%$ in adults $\geq 20$ years of age. The prevalence of CAD was 7.9 for men and $5.1 \%$ for women [40]. The higher figure in the US data may be due to differences in age, sample, survey methods, and criteria for diagnosis. The reported prevalence of $\mathrm{CAD}$ in the United Kingdom was $3.5 \%$ [41]; this figure was similar to our data on definite CAD.

As to the figures for definite CAD, only one study [7] reported the prevalence $(1.4 \%)$; they found no participant below the age of 45 years with definite CAD. However, it should be noted that the age range in this study was 25-64 years and the population was rural only. Compared to this, our data show an increase in the prevalence of definite CAD (0.9\%). Any CAD prevalence of $11.3 \%$ in urban and $13.2 \%$ in rural area respectively in our study was higher compared to some previous studies in the same age group and similar definition for CAD (8.1-9 \% for urban and 3.5-5 \% for rural) $[10,27,42,43]$. These data indicate an increase in the prevalence of any CAD over the past two decades. The increase in prevalence of any CAD may partially be due to improvement of treatment of CAD thus allowing better survival.

The urban prevalence data in this study may be comparable to other cities of India; however, the rural figures for prevalence may not be comparable to most rural areas in rest of India since rural Kerala is different from rest of rural India in social and economic development.

\section{Prevalence of coronary risk factors}

We found high prevalence of major conventional risk factors for CAD in our survey. The prevalence of various risk factors in our study like diabetes (15.2\%), hypertension $(28.4 \%)$, high cholesterol (52.3\%) and smoking in men $(28.1 \%)$ was comparable to the figures in a recent large study from Kerala, by Thankappan et al. [5]. The figures were also similar in the US adult population [44]. Physical activity in our study seems to be an overestimate due to the problems of self reports as has been reported by a recent study from Kerala [45].

\section{Limitations of the study}

Our study was the largest and most comprehensive contemporary community-based survey on the prevalence of CAD and its risk factors from India. The geographic spread of the survey enabled us to derive meaningful inferences of prevalence from the state. We could capture all the necessary data from participants with very little missing variables. One of the limitations for our study was the sub-optimal response rate, which could reach only $\sim 80 \%$; the response rate was lower in rural men. We could not capture the reasons for the poor response in men although we surmise that, being manual laborers many of them would be working on Sundays. As a result the sample consisted of higher proportion of women than in the general population. Sex disaggregated data will partly take care of this problem. There was significantly higher proportion of older individuals compared to the population of Kerala although age-adjustment in analysis would have removed this bias.

\section{Conclusion}

Our study revealed a high age-adjusted prevalence of CAD and coronary risk factors in Kerala, South India. Our study did not show any difference in the CAD prevalence in urban and rural population. Our data on prevalence of CAD are comparable to the figures from the US and the United Kingdom. Compared to previous Indian studies and the 1993 study of Kerala, this study showed higher prevalence of CAD in Kerala. The prevalence of definite $\mathrm{CAD}$ in Kerala increased nearly three times since 1993 without any difference in urban and rural areas. Most risk factors of CAD were highly prevalent in the state. Both population and individual level approaches are warranted to address the high level of CAD risk factors to reduce the increasing prevalence of CAD in this population.

\section{Abbreviations}

ACS: acute coronary syndrome; CHOD-PAP: cholesterol oxidase phenol 4-aminoantipyrine peroxidase; CABG: coronary artery bypass grafting; CAD: coronary artery disease; ECG: electrocardiogram; GOD-PAP: glucose oxidase/ peroxidase-phenol-4-amenophenazone method; HDL: high density lipoprotein; LDL): low-density lipoprotein; RAQ: rose angina questionnaire.

\section{Competing interests}

There has been no financial relationship with any company or any other funding source. The authors declare that they have no competing interest.

\section{Authors' contributions}

MNK, GZ, KV, PPM and SH conceptualized and designed the study. MNK lead the study in northern region, GZ in Central region, and SH in southern region. $\sqcup$ did the statistical analysis. All authors contributed to the writing of the manuscript, read the final version and approved it for submission.

\section{Acknowledgements \\ We thankfully acknowledge the Cardiological Society of India Kerala Chapter for the generous and exclusive funding of the study. We also appreciate the important intellectual input provided by Dr. Mark Huffman.}

\section{Dedication}

For the Cardiological Society of India Kerala Chapter Coronary Artery Disease and Risk Factors Prevalence (CSI Kerala-CRP) Study Investigators.

\section{Funding}

The study was funded exclusively by the Cardiological Society of India, Kerala Chapter; this is the professional organization of cardiologists in this region. The funding source had no role in the design, data collection, analysis or interpretation or writing up of the article. 


\section{Author details}

'Govt. Medical College, Kozhikode, Kerala, India. ${ }^{2}$ Mother Hospital, Thrissur, Kerala, India. ${ }^{3}$ Pushpagiri Hospital, Tiruvalla, Kottayam, Kerala, India. ${ }^{4}$ Westfort High-tech Hospital, Thrissur, Kerala, India. ${ }^{5}$ Sree Chitra Tirunal Institute for Medical Sciences and Technology, Trivandrum, Kerala, India. ${ }^{6}$ Department of Biostatistics, Christian Medical College, Vellore, Tamil Nadu, India. ${ }^{7}$ Achutha Menon Centre for Health Science Studies, Sree Chitra Tirunal Institute for Medical Sciences and Technology, Trivandrum Medical College, P.O. 695011 Thiruvananthapuram, Kerala, India.

\section{Received: 25 September 2015 Accepted: 8 January 2016} Published online: 14 January 2016

\section{References}

1. Gupta R, Guptha S, Sharma KK, Gupta A, Deedwania P. Regional variations in cardiovascular risk factors in India: India Heart Watch. World J Cardiol. 2012;4:112-20.

2. Gupta R, Joshi P, Mohan V, Reddy KS, Yusuf S. Epidemiology and causation of coronary heart disease and stroke in India. Heart. 2008;94:16-26.

3. Enas EA, Garg A, Davidson MA, Nair VM, Huet BA, Yusuf S. Coronary heart disease and its risk factors in first-generation immigrant Asian Indians to the United States of America. Indian Heart J. 1996:48:343-53.

4. Ahmed N, Bhopal R. Is coronary heart disease rising in India? A systematic review based on ECG defined coronary heart disease. Heart. 2005:91:719-25.

5. Thankappan KR, Shah B, Mathur P, Sarma PS, Srinivas G, Mini GK, et al. Risk factor profile for chronic non-communicable diseases: results of a community-based study in Kerala, India. Indian J Med Res. 2010;131:53-63.

6. Yusuf S, Hawken S, Ounpuu S, Dans T, Avezum A, Lanas F, et al. Effect of potentially modifiable risk factors associated with myocardial infarction in 52 countries (the INTERHEART study): case-control study. Lancet. 2004;364:937-52.

7. Kutty VR, Balakrishnan KG, Jayasree AK, Thomas J. Prevalence of coronary heart disease in the rural population of Thiruvananthapuram district, Kerala, India. Int J Cardiol. 1993;39:59-70.

8. Sivasankaran S, Thankappan KR. Prevention of non-communicable diseases requires a life course approach: a case study from Kerala. Indian J Med Res. 2013;137:874-7.

9. Zachariah G, Harikrishnan S, Krishnan MN, Mohanan PP, Sanjay G, Venugopal K, et al. Prevalence of coronary artery disease and coronary risk factors in Kerala, South India: a population survey-design and methods. Indian Heart J. 2013;65:243-9.

10. Mohan V, Deepa R, Rani SS, Premalatha G. Prevalence of coronary artery disease and its relationship to lipids in a selected population in South India: The Chennai Urban Population Study (CUPS No. 5). J Am Coll Cardiol. 2001;38:682-7.

11. World Health Organization. WHO STEPS Manual, WHO STEPS Surveillance, Part 2: Planning and Set Up; Section 2: Preparing the sample. 2008. p. 2-2-24-25.

12. Rose GA. The diagnosis of ischemic heart pain and intermittent claudication in field surveys. Bull World Health Organ. 1962;27:645-58.

13. Rose GA, Blackburn H. Cardiovascular survey methods. Monogr Ser World Health Organ. 1968:56:1-188.

14. World Health Organization. WHO STEPS Part 3, Training and practical Guides. Section 3: Guide to physical measurements (Step 2). 2008. p. 3-3-1-3-3-14

15. Ronald JP, Richards SC, Zhu-Ming Z. The Minnesota Code manual of electrocardiographic findings. Second edition Springer. 2010.

16. Mendis S, Thygesen K, Kuulasmaa K, Giampaoli S, Mähönen M, Ngu Blackett K, et al. World Health Organization definition of myocardial infarction:2008-09 revision. Int J Epidemiol. 2011;40:139-46.

17. American Diabetes Association. Diagnosis and classification of diabetes mellitus. Diabetes Care. 2010;33(1):S62-9.

18. Chobanian AV, Bakris GL, Black HR, Cushman WC, Green LA, Izzo Jr JL, et al. The Seventh report of the Joint National Committee on prevention, detection, evaluation, and treatment of high blood pressure: The JNC 7 Report. JAMA. 2003;289:2560-72.

19. Expert Panel on Detection, Evaluation, and Treatment of High Blood Cholesterol in Adults, Expert Panel on Detection, Evaluation, and Treatment of High Blood Cholesterol in Adults. Executive Summary of The Third Report of The National Cholesterol Education Program (NCEP) Expert Panel on detection, evaluation, and treatment of high blood cholesterol in Adults (Adult Treatment Panel III). JAMA. 2001:285:2486-97.

20. Misra A, Chowbey P, Makkar BM, Vikram NK, Wasir JS, Chadha D, et al. Consensus Statement for diagnosis of obesity, abdominal obesity and the metabolic syndrome for Asian Indians and recommendations for physical activity, medical and surgical management. J Assoc Physicians India. 2009:57:163-70

21. World Health Organization. Global recommendations on physical activity for health. Geneva: World Health Organization; 2010. http://www.whqlibdoc. who.int/ publications/2010/9789241599979_eng.pdf. Accessed 5 Dec 2015

22. International Institute of Population Sciences (IIPS), ORC Macro. National family health survey (NFHS -2), India, 1998-99. Mumbai: International Institute of Population Sciences; 2000.

23. Gupta R. Burden of coronary heart disease in India. Indian Heart J. 2005;57:632-8.

24. Sarvotham SG, Berry JN. Prevalence of coronary heart disease in an urban population in northern India. Circulation. 1968:37:939-53.

25. Chadha SL, Radhakrishnan S, Ramachandran K, Kaul U, Gopinath N. Epidemiological study of coronary heart disease in urban population of Delhi. Indian J Med Res. 1990;92:424-30.

26. Gupta R, Prakash H, Majumdar S, Sharma SC, Gupta VP. Prevalence of coronary heart disease and coronary risk factors in an urban population of Rajasthan. Indian Heart J. 1995:47:331-8.

27. Gupta R, Gupta VP, Sarna M, Bhatnagar S, Thanvi J, Sharma V, et al. Prevalence of coronary heart disease and risk factors in an urban Indian population: Jaipur Heart Watch-2. Indian Heart J. 2002;54:59-66.

28. Harris RB, Weissfeld LA. Gender differences in the reliability of reporting symptoms of angina pectoris. J Clin Epidemiol. 1991:44:1071-8.

29. Fischbacher CM, Bhopal R, Unwin N, White M, Alberti KG. The performance of the Rose angina questionnaire in South Asian and European origin populations: a comparative study in Newcastle. UK Int J Epidemiol. 2001:30:1009-16.

30. Patel DJ, Winterbotham M, Sutherland SE, Britt RG, Keil JE, Sutton GC. Comparison of methods to assess coronary heart disease prevalence in South Asians. Natl Med J India. 1997;10:210-3.

31. Singh RB, Sharma JP, Rastogi $V$, Raghuvanshi RS, Moshiri M, Verma SP, et al. Prevalence of coronary artery disease and coronary risk factors in rural and urban populations of north India. Eur Heart J. 1997:18:1728-35.

32. Kumar R, Singh MC, Singh MC, Ahlawat SK, Thakur JS, Srivastava A, et al. Urbanization and coronary heart disease: a study of urban-rural differences in northern India. Indian Heart J. 2006;58:126-30.

33. Hughes LO, Raval U, Raftery EB. First myocardial infarctions in Asian and white men. BMJ. 1989:298:1345-50.

34. Enas EA, Dhawan J, Petkar S. Coronary artery disease in Asian Indians: lessons learnt and the role of lipoprotein(a). Indian Heart J. 1997:49:25-34.

35. Gupta R, Gupta VP. Meta-analysis of coronary heart disease prevalence in India. Indian Heart J. 1996:48:241-5.

36. Kamili M, Dar I, Ali G, Wazir H, Hussain S. Prevalence of coronary heart disease in Kashmiris. Indian Heart J. 2007:59:44-9.

37. Latheef SA, Subramanyam G. Prevalence of coronary artery disease and coronary risk factors in an urban population of Tirupati. Indian Heart J. 2007;59:157-64

38. Jafar TH, Qadri Z, Chaturvedi N. Coronary artery disease epidemic in Pakistan: more electrocardiographic evidence of ischemia in women than in men. Heart. 2008:94:408-13.

39. Centers for Disease Control and Prevention (CDC). Prevalence of coronary heart disease -United States, 2006-2010. MMWR Morb Mortal Wkly Rep. 2011;60:1377-81.

40. Go AS, Mozaffarian D, Roger VL, Benjamin EJ, Berry JD, Blaha MJ, et al. Executive summary: heart disease and stroke statistics-2014 update: a report from the American Heart Association. Circulation. 2014:129:399-410

41. Townsend N, Wickramasinghe K, Bhatnagar P. Coronary heart disease statistics. London: British Heart Foundation; 2012. p. 82

42. Gupta R, Gupta HP, Keswani P, Sharma S, Gupta VP, Gupta KD. Coronary heart disease and coronary risk factors in rural Rajasthan. J Assoc Physicians India. 1994;42:24-6.

43. Gupta AK, Bharadwaj A, Ashotra S, Gupta BP. Feasibility and training of multipurpose workers in detection, prevention and control of coronary artery disease in apple-belt of Shimla hills. South Asian J Prev Cardiol. 2002;6:17-22 
44. Go AS, Mozaffarian D, Roger VL, Benjamin EJ, Berry JD, Blaha MJ, et al. Heart disease and stroke statistics-2014 update: a report from the American heart association. Circulation. 2014;129:e28-292. doi:10.1161/01.cir. 0000441139.02102 .80

45. Mathews E, Pratt M, Jissa VT, Thankappan KR. Self-reported physical activity and its correlates among adult women in the expanded part of Thiruvananthapuram City, India. Indian J Public Health. 2015;59:136-40.

Submit your next manuscript to BioMed Central and we will help you at every step:

- We accept pre-submission inquiries

- Our selector tool helps you to find the most relevant journal

- We provide round the clock customer support

- Convenient online submission

- Thorough peer review

- Inclusion in PubMed and all major indexing services

- Maximum visibility for your research

Submit your manuscript at www.biomedcentral.com/submit 